\title{
CASO TEORI ZAVASCKI: UMA ANÁLISE POLIFÔNICA DA MÍDIA
}

\section{TEORI ZAVASCKI CASE: A POLYPHONIC MEDIA ANALYSIS}

\author{
Leusa Cristina Bezerra dos Santos ${ }^{1}$ \\ Universidade Católica de Pernambuco
}

\section{RESUMO}

Este artigo mostra uma análise teórica em enunciados jornalísticos sob a perspectiva da polifonia. Utilizamos como aporte principal as concepções de Ducrot (1987) sobre a teoria polifônica da enunciação. Também recorremos aos entendimentos ideológicos de Bakhtin (2009). Em Orlandi (2009), embasamos as reflexões acerca do discurso. Trouxemos para esse estudo a notícia em dois meios de comunicação sobre a investigação da morte do ministro do Supremo Tribunal Federal, Teori Zavascki, em acidente aéreo. Discutimos o viés polifônico dos enunciados através das vozes que emanam. A pesquisa, que tem natureza descritiva e abordagem qualitativa, nos aponta que os enunciados jornalísticos analisados possuem uma forte característica de oposição. Pelo corpus observado e com base nas ideias ducrotianas, podemos atribuir esse movimento divergente das vozes dos enunciados a uma necessidade da mídia dialogar constantemente com um universo socio-histórico híbrido, que é a sua audiência. Universo esse que também absorve os organismos midiáticos e quem os faz.

PALAVRAS-CHAVE: polifonia; análise do discurso; enunciados jornalísticos.

\begin{abstract}
This paper shows a theoretical analysis in journalistic statements about polyphony perspective. We use the concepts of Ducrot (1987) on the polyphonic theory of enuntiation and we also fall back upon to Bakhtin (2009) ideological comprehension. In Orlandi (2009), we be based the considerations about discourse. Conducted to this essay the news about the plane crash that killed the Supremo Tribunal Federal judge, Teori Zavascki. Argue the polyphonic aspect of the propositions by the point of views that emanate. This study is descriptive and qualitative and shows us that the journalistic statements analyzed have a strong opposition character. From the corpus observed and based on the ducrotianas ideas, we can attribute this divergent movement of the voices of the statements to a necessity of the media to report constantly with a socio-historical hybrid universe because it is your spectators. Universe that cover the media and your operators.
\end{abstract}

KEYWORDS: polyphony; discourse analysis; journalistic statements.

\section{INTRODUÇÃO}

Ninguém diz nada sozinho. Tudo o que é dito o é de uma maneira coletiva, como se fosse produzido por um coral de indivíduos mergulhados em ideologias diversas. O discurso da mídia é um mar de discursos outros, convergentes e antagônicos. Os meios de comunicação veiculam uma

\footnotetext{
${ }^{1}$ Doutoranda em Ciências da Linguagem pela Universidade Católica de Pernambuco (Unicap). Mestra em Letras pela Universidade Federal de Pernambuco (UFPE). Jornalista graduada pela Universidade Católica de Pernambuco (Unicap).
} 
gama de discursos e ideologias que se confrontam e, ao mesmo tempo, refletem-se no diálogo social. Percebendo-se esse cenário rico em reflexões as quais colocam a língua como centro de questionamento, decidimos verificar, neste artigo, as várias vozes presentes em manchetes de jornais e as ideologias que articulam.

A manchete de capa de um jornal é a porta de entrada do leitor para esse veículo midiático e o cartão-postal deste para o leitor. Sob o ponto de vista jornalístico, podemos afirmar, com base em Traquina (2008), que a manchete é o componente principal da notícia. Traz em sua formação, que deve ser direta e concisa, os elementos necessários para que seja reconhecida e tratada como notícia jornalística.

Traquina (2008) afirma que um fato é notícia se agrega a si o que ele chama de "critérios de noticiabilidade". Segundo ele, esses critérios são "valores-notícia", um conjunto de características que determinam se um fato é ou não notícia, como também o seu potencial de relevância jornalística. Esses critérios são aplicados, no caso do jornal impresso, tanto para a manchete de capa, quanto para as outras matérias distribuídas ao longo das páginas do veículo. Seu uso também se estende para outras plataformas midiáticas, como sites, TVs, Rádio etc.

Desse modo, quando o tema reúne uma grande variedade de valores-notícia ou apresenta fortemente um ou alguns deles, pode ser escolhido como manchete de capa do jornal. Alguns dos principais valores-notícia que formam os critérios de noticiabilidade são: morte (critério considerado como fundamental), notoriedade (dos atores principais da notícia), proximidade (proximidade do acontecimento em termos geográficos e culturais), relevância (acontecimentos que têm um impacto na vida das pessoas), novidade (o que há de novo sobre determinado assunto ou o que de novo o assunto transmite), tempo (atualidade/aniversário do acontecimento); notabilidade (qualidade de ser visível e também o contrário do que é normal); inesperado (aquilo que surpreende a expectativa); conflito (violência física ou simbólica); infração (transgressão das regras). Um assunto pode reunir todos esses valores ou alguns, dependendo do tipo de informação.

A manchete de capa, por ser o elemento visual de maior destaque no jornal impresso, precisa agregar, de acordo com Traquina (2008), o máximo desses elementos para que tenha importância e faça frente aos concorrentes. Associando o peso jornalístico desse tipo de enunciado ao aspecto discursivo, podemos visualizar a forte relação jornalística com as ideologias e os segmentos sociais com os quais a mídia lida cotidianamente. E essa relação reflete-se na superfície textual e contextual dos enunciados.

Seguindo esse raciocínio, entendemos que a manchete de capa é um enunciado atravessado por discursos heterogêneos. O jornal enuncia algo na manchete, mas, além desse "algo" que está presente em primeiro plano, há também outros sentidos que emergem do enunciado. A partir dessa inquietação, encontramos na teoria polifônica da enunciação uma fonte fértil para investigar esse cenário discursivo.

Na sua teoria polifônica da enunciação, Ducrot (1987) debruçou-se em inicialmente em dois elementos essenciais: os pressupostos e subentendidos, que se constituem segundo o autor como a raiz desse aporte teórico. De modo resumido nesse item, podemos dizer, à luz das ideias do autor, que os pressupostos são as significações que estão ligadas ao sentido literal e ao contexto situacional do enunciado e são passíveis de refutação. E essa confrontação opera no campo dos subentendidos, que é a parte do enunciado oculta na superfície textual, mas que atua subliminarmente, refletindo ou refratando o enunciado principal.

São as manchetes de capa de jornais enunciados polifônicos que estabelecem um palco de lutas ideológicas entre suas várias possibilidades de interpretações? Um exame direcionado para esse modo de articulação linguístico-discursiva vai nos levar não só a responder a essa pergunta, como a entender o modus operandi ideológico que a mídia faz.

$\mathrm{Na}$ formação das suas ideias sobre polifonia, Ducrot (1987) chega aos elementos centrais do acervo teórico, que são os conceitos de sujeito falante, locutor e enunciador. No entanto, o 
autor deixa claro que não necessariamente o locutor seja o autor do enunciado. Ao sujeito falante é conferida essa tarefa.

Partimos de três hipóteses para esse estudo: (1) as manchetes de capa de jornais são polifônicas; (2) essa polifonia é essencialmente marcada pela oposição, ou seja, pela presença de vozes opostas, e (3) as vozes dessas manchetes dialogam com contextos sócio-históricos diferentes e são afetadas por esse universo híbrido.

Além das inúmeras possibilidades de interpretação das vozes de um enunciado que a teoria polifônica de Ducrot (1987) proporciona, utilizamos também o pensamento de Bakhtin (2009) ao tratar do campo ideológico. E como o discurso é um elemento que dialoga fortemente com as vozes dos enunciados, recorremos a Orlandi (2009) para estabelecermos o campo teórico discursivo, com os seus importantes conceitos sobre formação discursiva e interdiscurso. Esses campos são fundamentais para o entendimento das vozes e raízes ideológicas dos enunciados.

\section{Pressupostos e subentendidos: raízes da polifonia}

Os pressupostos e subentendidos são a base da concepção polifônica de Ducrot (1987). Constituem-se no primeiro tangenciamento analítico de um enunciado e permitem a identificação inicial de sujeitos discursivos, formações discursivas presentes e conceitos ideológicos emergentes de determinada construção linguístico-contextual.

Ao se debruçar acerca desses dois elementos Ducrot (1987) chegou ao amadurecimento para a teoria polifônica da enunciação. As várias vozes de um discurso, que são o centro da teoria polifônica, foram identificadas por Ducrot (1987) através do estudo e conceituação dos pressupostos e subentendidos.

Ducrot (1987) faz, inicialmente, uma diferenciação entre pressuposto e subentendido por julgá-los indispensáveis na análise de um enunciado. Mais tarde ele faria um reexame desses conceitos, mas não os tornaria inválidos, uma vez que são reformulados, mas não abandonados. Segundo o autor, o pressuposto não nega o enunciado principal e está preso ao sentido literal. Já o subentendido pode negar o enunciado principal e até se exclui do sentido literal. Para o autor, "o subentendido permite acrescentar alguma coisa sem dizê-la, ao mesmo tempo em que ela é dita" (p. 19). Ao passo que o pressuposto é apresentado como "uma evidência do enunciado que foi posto" (p. 20).

Comparando com os elementos da sua teoria polifônica, Ducrot (1987) explica que o que é posto no enunciado é o que o locutor afirma. Já o que está subentendido faz parte da conclusão do ouvinte do enunciado. E o que é pressuposto é apresentado como informação comum tanto ao locutor quanto ao ouvinte. Para situar linguística e discursivamente os pressupostos e subentendidos, o autor faz uma analogia com os pronomes quando coloca que o posto está para o "eu", o subentendido está para o "tu" e o pressuposto está para o "nós".

Com base nessa distinção, pode-se levar em conta que os subentendidos servem muito bem ao locutor quando este quer se eximir da responsabilidade do que disse, deixando para o ouvinte a conta e o risco da interpretação. Já em relação ao pressuposto, o locutor enuncia e transfere junto com este enunciado um significado "literal" (grifo da autora). O pressuposto seria, portanto, um componente linguístico, ou seja, está situado na língua. O subentendido é um componente retórico, que emerge do enunciado por meio da reflexão do destinatário.

Ducrot (1987) observa, no entanto, que os pressupostos e subentendidos atuam juntos no enunciado. Especificando melhor, afirma que "os pressupostos encontram-se entre os dados que devem ser fornecidos à entrada do componente retórico" (p. 25). Torna-se, portanto, necessário o conhecimento prévio dos pressupostos para atingir o subentendido. É como se os pressupostos fossem a porta de entrada para identificar e assimilar os subentendidos. 
Antes do reexame dos conceitos relativos a pressupostos e subentendidos, Ducrot (1987) admitia que o pressuposto fosse determinado pela frase e que todos os pressupostos de um enunciado já estariam previstos na significação da frase. Quanto ao subentendido, ele observava que este não está presente na frase, mas no momento da enunciação. Desse modo, um enunciado pode remeter a um subentendido na situação $\mathrm{X}$ e a outro subentendido na situação $\mathrm{Y}$. $\mathrm{O}$ subentendido está preso ao sentido do enunciado enquanto que o pressuposto é ligado e gerado por meio da significação da frase ${ }^{2}$.

O que Ducrot (1987) mudou na revisão conceitual é que o pressuposto não está apenas vinculado à frase, mas também está ligado ao contexto situacional em que o enunciado é proferido. Ele apresenta, a partir desse momento, que um enunciado considerado subentendido pode ser um pressuposto, dependendo do objetivo do locutor. Se um locutor L diz um enunciado X com o objetivo Y, há o pressuposto A e o subentendido B. Mas se o objetivo do locutor é outro (Y'), então o subentendido B pode virar um pressuposto.

Para chegar a essa conclusão, o autor fez uma analogia da relação entre pressuposição e ato ilocutório, ou ilocucionário. Esse elemento integra a teoria dos atos de fala, que surgiu na Filosofia da Linguagem e depois foi adotada pela Pragmática. Essa concepção entende a linguagem como forma de ação compreendida em três tipos de atos: o locucionário, o ilocucionário e o perlocucionário.

O locucionário é a emissão de alguma mensagem compreensível, dentro de determinado vocabulário e regras gramaticais. O perlocucionário é responsável pelo convencimento, ou seja, é o efeito que se produz ou se tenta produzir no ouvinte ao emitir uma mensagem. O ilocucionário define a natureza da ideia que o falante quis exprimir. Ducrot (1987) partiu do princípio de que o ato ilocutório traz justamente a intenção do locutor em possibilitar determinado entendimento por parte do ouvinte e que esse entendimento pode ser diferente.

No entanto, dentro do campo dos atos de fala, Austin (1995), um de seus principais teóricos, centra a importância do convencimento no ato perlocucionário. Para o britânico, é nesse tipo de ato que ocorre a persuasão, o convencimento até sobre "fatos enganosos" (AUSTIN, 1955, p. 109). Analisando o foco que Ducrot (1987) dá ao ato ilocutório, observamos que o autor centrou seu olhar para o contexto em que o locutor se apropria para construir uma impressão ao seu ouvinte. E, assim, a etapa perlocucionária, que é a do convencimento, é o efeito dessa construção.

Esse raciocínio, afirma Ducrot (1987), também ocorre no terreno da pressuposição. O locutor profere um enunciado com determinado pressuposto, mas, dependendo da situação, o ouvinte vai construir outro sentido do que foi dito e esse pressuposto pode ser outro, ou até passar a ser um subentendido. Desse modo, Ducrot (1987) entende que se obtém o pressuposto não só a partir da frase, mas da situação de enunciação. Quanto ao subentendido, parece ter ficado mantida a característica discursiva de sua conceituação, ou seja, do que é dito sem dizê-lo literalmente.

Ducrot (1987) também reformula a noção do teste clássico da negação e da afirmação para descobrir um pressuposto. Partindo do princípio de que poucas frases podem ser negadas ou interrogadas, ele introduz a noção de encadeamento discursivo. Ou seja, o enunciado gera pressupostos de acordo com aquilo a que este se refere. Em outras palavras, ele sustenta que o sentido do discurso, o qual é construído em um enunciado, é o que garante a sustentação a um pressuposto e a outro não. Mais uma vez, vê-se que o teórico põe a situação de enunciação como elemento-chave para a identificação de pressupostos e subentendidos.

Por fim, ele sugere que, para descobrir os pressupostos de um enunciado, devem ser aplicados os critérios clássicos para a frase e também o encadeamento para o enunciado. Atentando, então, para o fato de que nem sempre os dois caminhos levam às mesmas pressuposições. Essas,

\footnotetext{
${ }^{2}$ Nesta consideração, Ducrot adotou o seguinte conceito de "frase" e "enunciado": "A frase é uma entidade gramatical abstrata, e o enunciado é uma realização particular da frase. O sentido é o valor semântico do enunciado, a significação, o valor semântico da frase" (1987, p.31, nota de rodapé).
} 
conforme Ducrot (1987), são um veículo para o discurso. Possibilitam aos interlocutores dizerem uma coisa e não outra.

Com base nesse reexame, o autor refina a noção de pressuposto e subentendido. Ele parte do princípio de que as duas noções, apesar de estarem em níveis diferentes, não se opõem. Ducrot (1987) situa a pressuposição como integrante do sentido dos enunciados. O subentendido é a maneira como esses sentidos são interpretados pelo destinatário. A pressuposição, portanto, é o que não se diz no dito e o subentendido é o que se diz subliminarmente, através de "outros".

\section{A polifonia em Ducrot}

"Polifonia" é uma expressão que Ducrot (1987) tomou emprestada de Bakhtin para nomear a sua teoria. A teoria polifônica estabelece que de um enunciado emergem várias vozes, tanto convergentes quanto divergentes. Essa variação depende de fatores extralinguísticos, como a(s) formação (ões) discursiva(s) da(s) qual(is) se origina determinado enunciado, assim como a ideologia em que se ancora e o contexto sócio-histórico no qual um enunciado aparece.

O exercício teórico que Ducrot (1987) realizou para chegar aos conceitos de pressuposto e subentendido formou o alicerce de ideias para o desenvolvimento e constituição da teoria polifônica da enunciação. E essa aproximação entre os conceitos de pressupostos e subentendidos e a polifonia é fácil de ser reconhecida quando se focam os implícitos. Na verdade, os implícitos subentendidos - muito mais do que os pressupostos - são a raiz da polifonia.

"Polifonia", como o próprio termo sugere, remete às várias vozes existentes em uma situação de comunicação. Ducrot (1987) faz distinções entre as pessoas das quais as diferentes vozes se originam. Ele introduz os conceitos de sujeito falante, locutor e enunciador. Apresenta o locutor como responsável pela enunciação, o que não significa que esse locutor seja o autor do enunciado. Essa tarefa Ducrot (1987) atribuiu ao sujeito falante, ou falante. Ao enunciador cabe a tarefa de ser a personagem que atua na enunciação. Ducrot (1987) aponta, no entanto, a possibilidade de uma identificação discursiva entre locutor e enunciador, que podem ser a mesma pessoa ou pessoas diferentes:

Todo o paradoxo - que denomino conforme a expressão de Bakhtin "polifonia" prende-se ao fato de que os enunciadores não se confundem automaticamente com o locutor. Se um enunciador é assimilado ao locutor, isto se dá em virtude de uma identificação particular, e a identificação pode do mesmo modo assimilar tal ou qual enunciador com outras personagens que não o locutor, por exemplo, com o alocutário (p. 142).

O locutor é o responsável pelo enunciado, sem necessariamente este (o enunciado) ser assimilado àquele (o locutor), postula Ducrot (1987). Ele caracteriza o locutor como uma pessoa que mostra o enunciador, mas ambos, necessariamente, não são a mesma pessoa e, sendo diferentes, podem discordar entre si, como claramente coloca o linguista francês: “... ele (o locutor) introduz em seu discurso uma voz que não é forçosamente a sua” (DUCROT, 1987, p. 144).

Pode-se dizer em relação a esse recorte que um discurso introduzido por um locutor $\mathrm{L}$ pode ter ou não a voz desse locutor e de um ou mais de um enunciador E. Nesse cenário, tanto L quanto E podem ter pontos de vista convergentes ou divergentes, embora seja na divergência, na oposição, que eles são mais facilmente identificáveis. Esse afastamento de opiniões é o que Ducrot (1987) chama de distanciamento entre locutor e enunciador.

Contudo, para validar um enunciado, o locutor, na visão do francês, precisa ter uma autoridade argumentativa. Esta se baseia numa tese desenvolvida por Ducrot dentro da concepção polifônica chamada de "arrazoado por autoridade". Sua premissa principal está alicerçada no princípio de que um enunciado, para ter validade, precisa que um enunciado anterior o assevere na 
mesma cena de enunciação. Ou seja, para o locutor L dizer P e este P ser válido, é necessário que um enunciado anterior, proferido por um enunciador $\mathrm{X}$, o assevere.

Em matérias jornalísticas isso é muito comum. Quando, por exemplo, o repórter (L) escreve sobre um fato $(\mathrm{P})$, baseia-se em afirmações de terceiros $(\mathrm{X})$, que, por sua vez, asseveram o fato $(\mathrm{P})$. Os textos jornalísticos constituem uma enorme fonte de exemplos porque trabalham o tempo todo com discursos diretos e indiretos, além de paráfrases. Um exemplo desse arrazoado por autoridade pode ser representado pelo seguinte trecho da notícia abaixo:

\section{FAB diz que análise preliminar da caixa-preta não aponta 'anormalidade' no avião que caiu com Teori ${ }^{3}$}

(Portal G1. 24.01.2017)

$\mathrm{O}$ acidente tratado pelo texto refere-se à queda da aeronave que matou o ministro do Supremo Tribunal Federal, Teori Zavascki, e mais quatro pessoas, ocorrido no dia 19 de janeiro de 2017, em Paraty, Rio de Janeiro. O desastre gerou um clima de comoção no país e de expectativa porque o magistrado era o relator da Lava Jato no Supremo, operação que investiga o desvio de dinheiro da Petrobras e envolve políticos com mandato e empresários.

O desastre aéreo traz consigo vários valores-notícia importantes, que se inter-relacionam. A morte de um ator jurídico, no caso o ministro Teori Zavascki, coloca em evidência dois critérios bastante caros ao universo midiático: a morte e a relevância do fato. Notoriedade também se junta a esses critérios devido ao peso político da figura do magistrado vitimado. Além desses, outros valores somam-se ao fato como a proximidade - um acidente desse porte numa praia turística do Rio de Janeiro - e, evidentemente, o inesperado.

Todos esses fatores agregam ao acontecimento um caráter de importância jornalística, com prognósticos de perdurar por longo tempo já que os desdobramentos do assunto irão continuar abastecendo o noticiário. Além disso, logo que ocorreu o acidente, houve grande manifestação nas redes sociais com vários pontos de vista. O mais comentado e discutido no ambiente virtual foi a suspeita de que o acidente teria sido provocado porque o ministro vitimado fatalmente tratava do caso com imparcialidade, o que desagradaria setores políticos envolvidos no esquema de corrupção na Petrobras, chamado de Petrolão.

No exemplo acima, o repórter que redigiu o texto representa o locutor (L). O assunto tratado é a declaração da Força Aérea Brasileira (FAB) sobre a análise preliminar da caixa-preta, o que seria o fato $(\mathrm{P})$. No entanto, para asseverar o que afirmou, o repórter $(\mathrm{L})$ se ampara no discurso da FAB que, nesse caso, representa o enunciador $\mathrm{X}$, que, por ser um órgão público e estar à frente das investigações, carrega consigo a autoridade de fala. Ou seja, o arrazoado por autoridade está situado na FAB, mesmo que esta não seja a autora do enunciado principal. Nesse exemplo temos, portanto, locutor e enunciador diferentes. O locutor sendo o jornalista que apurou e redigiu a manchete e o enunciador a FAB, cuja afirmação é a base discursiva do material jornalístico.

A figura do locutor, segundo Ducrot (1987), possui uma identidade discursiva tal que o que ele enuncia ou faz enunciar não necessariamente parte de seu ponto de vista. Em outras palavras, o que o locutor $(\mathrm{L})$ diz pode ser um dito a partir de outra figura do discurso, o enunciador $(\mathrm{E})$. $\mathrm{O}$ enunciador, por seu turno, é outra voz do discurso, que diz o que o locutor (L) não assume para si ou com o que não quer concordar. $\mathrm{O}$ alocutário, nessa relação, parece ser uma voz à qual o discurso é direcionado, mas é também a voz que fala nesse mesmo discurso.

É nesse cenário de relação de vozes que se fundamenta o "arrazoado por autoridade". O termo que Ducrot (1987) criou remete, em verdade, a um conjunto de mecanismos através dos quais é possível asseverar um enunciado por meio de outras vozes presentes nele. A promessa do arrazoado por autoridade permite retomar a fala de outrem (uma pessoa X, como classifica Ducrot),

3 . Disponível em: http://zip.net/bxtDFb. Acesso em: 24.01.2017. 
encadeá-la em uma origem enunciativa diferente e mostrá-la como produzida por uma vOz diferente da encontrada em X.

Dessa forma, cabe o raciocínio de que pode apropriar-se de um discurso, trabalhá-lo, levando-se em conta razões específicas em um contexto determinado, e projetar esse discurso com marcas de origem enunciativa diferente do discurso original. Ducrot (1987), no entanto, não nega que essa articulação enunciativa deixa marcas através das quais se pode identificar a origem discursiva de um enunciado. Portanto, o locutor, o enunciador e o alocutário - este último também podendo assumir a condição de um enunciador - são vozes diferentes que constituem um enunciado. Essa é a essência da teoria polifônica da enunciação.

Retomando o exemplo anterior, podemos visualizar a aplicabilidade desse raciocínio:

FAB diz que análise preliminar da caixa-preta não aponta 'anormalidade' no avião que caiu com Teori ${ }^{4}$

(Portal G1. 24.01.2017)

O locutor L, já identificado anteriormente, é o jornalista que redigiu essa manchete. $\mathrm{O}$ enunciador $\mathrm{E}$ situa-se na figura da $\mathrm{FAB}$, através da qual $\mathrm{L}$ afirma o que não pode asseverar por autoridade própria. A análise da caixa-preta é um assunto de extrema expectativa porque o conteúdo da gravação de voz dos últimos momentos do voo pode ser ou não revelador quanto às causas do acidente.

O repórter (locutor L) não pode afirmar que a gravação não aponta irregularidade, até porque não tem autoridade para tal. Mas recorre à $\mathrm{FAB}$ (enunciador $\mathrm{E}$ ) para isso. Mas esse aparente afastamento discursivo do locutor $\mathrm{L}$ não o exime de compartilhar uma aproximação interpretativa do enunciador E. O alocutário, que chamaremos de A, é uma voz, como afirma Ducrot (1987) na discussão teórica, que aparentemente não fala, mas sua atuação é percebida porque é a voz para a qual é direcionado o enunciado.

Esse alocutário A é aquele que se informa dos fatos, que quer saber se o acidente foi ou não sabotagem. É a audiência do portal. Por isso, o cuidado jornalístico em procurar marcas enunciativas de aparente distanciamento entre o que dizem locutor L e enunciador. No exemplo em análise, o jornalista utilizou-se do discurso indireto ao afirmar que "A FAB diz que", mostrando que o enunciado origina-se da avaliação do órgão investigativo.

\section{A polifonia e a perspectiva bakhtiniana}

Ducrot (1987) parte do conceito de polifonia em Bakhtin para elaborar a base de sua teoria polifônica da enunciação, estabelecendo, contudo, uma diferenciação entre a visão bakhtiniana e a sua. Para Bakhtin (2009), todo discurso é atravessado por discursos outros. O que é dito é direcionado a algo ou alguém, responde ou reproduz algo do passado e se posiciona para algo no futuro. O tempo cronológico da linguagem humana dá lugar ao tempo histórico-discursivo e deste passa a ser um coadjuvante.

O discurso, na concepção bakhtiniana, é ocupado por vozes diferentes. O mundo interior ou exterior está sempre em contato com pontos de vistas de outros, atravessado por visões alheias, mas que lhe são constitutivas. A dinamicidade da relação com o outro é bem marcada por Bakhtin em vários momentos de sua obra, como em Problemas da Poética de Dostoiévski:

As relações de reciprocidade com a palavra do outro no contexto vivo e concreto não têm caráter estático, mas dinâmico: a inter-relação das vozes no discurso pode variar acentuadamente, o discurso orientado para um único fim pode converter-se em discurso 
orientado para diversos fins, a dialogação interna pode intensificar-se ou atenuar-se; o tipo passivo pode tornar-se ativo, etc. (2010b, p. 228).

Bakhtin (2010b) escreve esse trecho quando fala da impossibilidade de esgotar os modos de ocorrência do discurso do outro. Mas faz uma classificação atendendo à necessidade de estabelecer que a palavra concreta pode pertencer a diversas variedades e tipos de discursos. No entanto, o autor reflete profundamente sobre essa ocorrência de vozes outras, submetendo o raciocínio aos textos literários. Ducrot (1987) apropria-se desses conceitos e acrescenta-os aos seus estudos.

Essa aplicação proposta por Ducrot (1987) não é uma crítica ao trabalho de Bakhtin, mas a tomada de um corpus diferente dos textos literários estudados pelo russo. Como o objeto de análise quanto ao aspecto polifônico da enunciação é o enunciado, faz-se necessário distinguir os domínios deste em relação à frase. Adotada a conceituação de Ducrot (1987), pode-se associar a frase a um objeto da gramática e, sendo da gramática, através dela - da frase - aparece o enunciado.

O enunciado, por sua vez, é o "acontecimento da frase" (ibid., p. 164). Para Ducrot (1987), o enunciado extrapola o linguístico e situa-se nos âmbitos contextual, social e discursivo. O enunciado é uma marca de um discurso ou de "um fragmento de discurso" (p. 166). Efetivamente, uma frase acontece de modo diferente em enunciados situados em contextos distintos.

Essa importância do contexto para a interpretação de um enunciado também é destacada por Maingueneau (2002). Segundo ele, "compreender um enunciado não é somente referir-se a uma gramática e a um dicionário, é mobilizar saberes diversos, fazer hipóteses, raciocinar, construindo um contexto que não é um dado preestabelecido e estável” (p. 20).

Desse modo, pode-se inferir que o contexto de um enunciado é um elemento determinante para a assimilação de quem o lê. E esse contexto é híbrido, ou seja, não é formado homogeneamente por um tipo de discurso, mas é atravessado por uma infinidade de discursos, também antagônicos entre si.

O resultado das diferentes vozes em um discurso, das ações dos agentes envolvidos - sejam eles locutor, enunciador ou sujeito falante - convergem para a enunciação. Para Ducrot (1987), a enunciação é um acontecimento histórico, "constituído pelo aparecimento de um enunciado" (p. 168). E este acontecimento não é produto de um sujeito-autor, mas, na sua essência, é um enunciado que acontece.

O sujeito do enunciado não é único. A unicidade do sujeito falante não se sustenta. Ducrot (1987) atribui ao locutor L a marca de primeira pessoa. Mas, mesmo essa característica não garante que o locutor L pode estar falando. Segundo o linguista francês, L pode também ser acompanhado por outra voz, a de um enunciador E, ou mais de um. Assim sendo, segundo a teoria polifônica de Ducrot (1987), tem-se pelo menos dois tipos de personagens envolvidos numa enunciação: o locutor e o enunciador.

O locutor L é o ser ao qual é atribuída a responsabilidade pelo enunciado, como já foi dito anteriormente neste trabalho. Uma marca evidente da sua presença é o pronome "eu" e outros sinais que evidenciem o aparecimento da $1^{a}$ pessoa. O autor também alerta para a possibilidade de um enunciado ser atravessado por mais de um locutor, mas isso não invalida o método de identificação dos "locutores" enquanto seres responsáveis pelo enunciado.

No entanto, nem sempre L é o produtor do enunciado. Este, o produtor, seria o que Ducrot (1987) chama de "autor empírico" do enunciado, ou "autor real", ou "sujeito falante". Locutor e autor empírico podem ser pessoas diferentes porque falam de lugares diferentes e têm papéis diferentes numa enunciação, ou podem ser a mesma pessoa, desempenhando funções distintas em determinada enunciação. Cabe ao autor empírico, portanto, ser o autor real do enunciado. O locutor L é uma ficção discursiva, que só existe enquanto responsável pelo enunciado, como esclarece Ducrot (1987). 
Da noção de locutor, Ducrot (1987) desmembra esse ser em L (locutor enquanto tal) e L' (locutor enquanto ser no mundo). L continua sendo, portanto, o responsável pela enunciação e L' é o ser que o pronome "eu" designa, embora este só seja identificável através de "L". O L, portanto, não assume uma posição no enunciado, deixando para L' essa tarefa. Pode se dizer que L' é a parte que se posiciona no enunciado, diferentemente de L, que não assume posições, apenas as enuncia. Essa distinção dentro da figura do locutor é a primeira forma de polifonia em casos classificados por Ducrot (1987) como sendo de "dupla enunciação" (p. 191). Contudo, em enunciados onde não há essa ocorrência, L e L' se fundem.

Existe ainda a segunda forma de polifonia por meio da qual Ducrot (1987) introduz a figura do enunciador $\mathrm{E}$, bem mais frequente que a primeira descrita no parágrafo anterior. Conforme o linguista, o enunciador é o ser que se manifesta através da enunciação sem que a ele seja atribuída a palavra. Ou seja, o enunciador não fala no enunciado, mas é "falado". O enunciador é, por exemplo, uma opinião que emerge discursivamente de um enunciado.

O enunciador é, em essência, uma figura marcada pela subjetividade. É um sujeito que não é o sujeito real e nem o ficcional, mas outro tipo de sujeito: aquele que expressa visões outras, antagônicas, irônicas, enfim, diferentes do que é dito por L.

E, dentro da possibilidade de várias perspectivas, à negação é dado um lugar de destaque na teoria polifônica de Ducrot (1987). Segundo ele, um enunciado com marcas de negação faz aparecer mais facilmente o seu contraponto afirmativo. Já o contrário não ocorre dessa forma. Em um enunciado afirmativo, a sua contraparte negativa fica mais próxima à subjetividade, embora também seja passível de identificação.

Mas sobre esse aspecto é importante fixar-se que em todo enunciado - seja negativo ou afirmativo - há o seu contraponto. E essa identificação significa a identificação dos enunciadores envolvidos no enunciado, além do locutor, que pode estar distanciado de um enunciador e assimilar o ponto de vista de outro enunciador. Estabelecer que para cada afirmação ou negação exista o seu respectivo contraponto é identificar em um discurso as várias vozes que dele emergem.

Para melhor explicar a noção de locutor e enunciador, delimitando suas fronteiras, Ducrot (1987) faz comparações com o teatro: "Direi que o enunciador está para o locutor assim como a personagem está para o autor" (p. 192). Dessa forma, o enunciador é uma figura mais ficcionista do que o locutor, pois este ainda pode coincidir ou não com o autor real, mas aquele (enunciador) é fruto do sentido discursivo do enunciado. Essa comparação com o teatro decorre das ideias da teoria da narrativa, apresentada em 1972 pelo crítico literário francês Gérard Genette, do qual Ducrot (1987) se baseia e relaciona-as aos elementos da sua teoria polifônica da enunciação.

O autor em Genette corresponde ao sujeito falante em Ducrot (1987). É o produtor efetivo do enunciado, mas que permanece exterior ao sentido deste. Com o narrador, em Genette, identifica-se, em Ducrot (1987), a figura do locutor, que é aquele responsável pelo enunciado, o produtor ficcional do enunciado. Integra a essa relação entre autor e sujeito falante a figura do enunciador E que, para Ducrot (1987), corresponde ao ponto(s) de vista (s) do enunciado, que necessariamente não é o mesmo do locutor ou do sujeito falante. Esses elementos não são correlacionados apenas conceitualmente, mas também funcionalmente, como bem esclarece Ducrot (1987):

\footnotetext{
O locutor fala no sentido em que o narrador relata, ou seja, ele é dado como a fonte de um discurso. Mas as atitudes expressas neste discurso podem ser atribuídas a enunciadores de que se distancia - como os pontos de vista manifestados na narrativa podem ser sujeitos de consciência estranhos ao narrador (p. 196)
}

A figura do enunciador possibilita ao sujeito falante e ao locutor expressarem ideias das quais eles não querem assumir a autoria. Essa característica é muito explorada no discurso das mídias, que recorrem à estratégia de atribuir a outro o que foi escrito em determinada manchete ou 
matéria jornalística. A identificação das três figuras da teoria polifônica de Ducrot (1987) - sujeito falante locutor e enunciador - e uma análise de como as vozes dessas figuras aparecem em um discurso e o que dizem possibilitam ao analista desconstruir um enunciado e recuperar as origens discursivas e ideológicas deste.

\section{Ideologia e discurso}

Bakhtin (2009) compreende a enunciação como uma réplica do diálogo social. Sendo dessa natureza é, portanto, ideológica. O diálogo social se origina nos signos, elementos aos quais são atribuídos valores, conceitos específicos em contextos específicos. O signo, por sua vez, está intimamente associado à palavra. A palavra é o elemento que liga um objeto a um símbolo, que dá significação a este objeto. Todo signo é ideológico, postula o autor russo. E a palavra é o componente mais representativo do signo, é um essencial condutor da ideologia porque é através dela que se instala uma arena de relações sociais.

Tem-se, então, um ciclo na enunciação: a palavra, o objeto, a significação dada ao objeto e o signo. A articulação desses itens é, então, a responsável pela natureza ideológica do signo. E pode-se dizer, à luz de Bakhtin (2009), que a ideologia determina a língua, a consciência, a atividade mental, enfim, a ideologia está no núcleo das relações sociais. A discussão da ideologia em Bakhtin passa pelo signo, que é eminentemente ideológico, mas o filósofo russo considera que: "Tudo que é ideológico possui um significado fora de si mesmo". (2009, p. 31). Ou seja, há em um signo um significado dentro de sua realidade que também é refratado e remetido em uma realidade exterior ao mesmo.

Há na relação indivíduo-sociedade-ideologia uma troca constante, de convergências e divergências. E a linguagem é o terreno clássico para essa manifestação. A palavra, escrita ou falada, é essencialmente um fenômeno ideológico. É a manifestação mais essencial da ideologia. Por meio da palavra transmitem-se ideias, conceitos, valores e influências. Através da palavra transmite-se ideologia.

Em Bakhtin (2009), pode-se entender o significado de ideologia como o conjunto de ideias, valores, crenças que conduzem, reformulam, formam ou refratam em determinada estrutura social, que, por sua vez, está inserida em relações de poder. E, para o pensador russo, o indivíduo, por ser uma entidade social, não está livre das ideologias que permeiam o seu extrato social.

A ideologia, no entanto, não age só. Ela atua através de um instrumento, que é o discurso, o qual pode carregar uma ou várias ideologias. O discurso é tão multifacetado quanto a própria ideologia. Orlandi (2009) discute o discurso dentro de uma relação de interação com outros elementos: a significação entre sujeitos e a inscrição desses sujeitos dentro de formações discursivas diversas, heterogêneas.

O discurso não é apenas uma troca de diálogo entre indivíduos. Segundo Orlandi (2009), dois sujeitos que se comunicam entre si trocam muito mais do que palavras. Trocam valores, conceitos, ideias. O conceito de discurso, para a autora, está situado nessa relação essencial: "é efeito de sentido entre locutores" (idem, p. 21).

Os dizeres que os interlocutores produzem são mais do que meras mensagens. O que é dito traz consigo também pistas de crenças, valores e conceitos nos quais os interlocutores acreditam, ou seja, os dizeres contidos no discurso dão pistas das formações ideológicas em que se criaram. Os indivíduos, a enunciarem algo, se apropriam e são apropriados por ideias outras, exteriores ao dizer. Entre suas palavras o falante traz palavras de outros. Essa relação do discurso de um falante com discursos de outrem toca em outro elemento presente nessa teia de relações discursivo-sociais: a formação discursiva. Esta é a chave para compreender o sentido de um discurso e em que formação ideológica ele está inserido. 
A formação discursiva possibilita ao discurso ter determinada assinatura ideológica e não outra como pontua a autora: "A formação discursiva se define como aquilo que numa formação ideológica dada - ou seja, a partir de uma posição dada em uma conjuntura sócio-histórica dada determina o que pode e deve ser dito" (ORLANDI, 2009, p. 43). Esse processo de determinação do que é dito é constituído por dois fatores essenciais para que a atuação da formação discursiva seja identificada.

O primeiro fator é a própria influência da formação discursiva na significação do que é dito. As palavras não são apenas palavras. Elas representam um sentido de acordo com determinada formação discursiva e não outro. Ou seja, em outra formação discursiva, as mesmas palavras que foram ditas podem ter um significado diferente. Desse modo, o significado do que é dito não está nas palavras, mas no que elas significam em determinado momento sócio-histórico, em determinada ideologia. As palavras, portanto, "falam com outras palavras" (idem).

Outro fator é a possibilidade de compreender o que é dito e significar esse "dito" de acordo com a formação discursiva. É através da formação discursiva que se pode ter a compreensão dos inúmeros discursos produzidos por um falante, seja ele indivíduo ou instituição social.

Os sujeitos socialmente situados e historicamente atuantes produzem a partir de formações discursivas específicas de cada um deles. Porém, em que situação eles produzem esses discursos? Essa situação é chamada de condições de produção. Para Orlandi (2009), essas condições de produção estão situadas justamente nos sujeitos e na situação sócio-histórica e ideológica em que esses sujeitos produzem os discursos.

Os sujeitos recorrem a formações discursivas e a condições de produção para produzir os discursos. No entanto, há um terreno - cujos limites são muito tênues - a que esses sujeitos também recorrem para entrar em contato com as formações discursivas: o interdiscurso. $O$ interdiscurso se caracteriza por reunir dizeres já ditos em outro lugar e esquecidos. Dizeres estes que são incorporados pelos indivíduos através da formação discursiva. O interdiscurso, portanto, abriga formações discursivas. O interdiscurso, como Orlandi (2009) afirma, é a memória discursiva esquecida, mas presente e à qual o indivíduo recorre para acionar uma formação discursiva e não outra.

Essa articulação de sujeitos afetados por ideologias e recorrendo ora a uma, ora a outra formação discursiva com a existência de várias vozes em um enunciado, segundo a teoria polifônica de Ducrot (1987), enriquece o cabedal teórico de análise e identificação de dizeres híbridos nos enunciados jornalísticos.

No próximo item, vamos analisar o mesmo assunto noticioso publicado em dois diferentes meios de comunicação e investigar os discursos e vozes articulados nesses enunciados ${ }^{5}$.

\section{Caso Teori: uma análise}

Apresentamos para estudo e aplicação das teorias discutidas três excertos jornalísticos de empresas de comunicação diferentes, mas sobre o mesmo assunto. Trata-se da análise preliminar da gravação durante o voo que matou o ministro do STF, Teori Zavascki, e mais quatro pessoas. A Aeronáutica divulgou em seu site, no dia 24 de janeiro de 2017, que recuperou com sucesso o áudio e não identificou qualquer anormalidade nos sistemas da aeronave, ressalvando que essa foi uma análise inicial, conforme o órgão esclarece.

No mesmo dia em que a notícia foi disponibilizada no site federal, os meios de comunicação replicaram-na e repercutiram-na ostensivamente. Coletamos esse material dos sites do O Globo,

\footnotetext{
${ }^{5}$ Selecionamos um assunto para enquadrar o trabalho no propósito desse artigo, mas preservamos os elementos de estudo teórico, o que garante a profundidade do fazer científico.
} 
Estado de S. Paulo e do jornal impresso Diario de Pernambuco. Expomos também a notícia publicada no site oficial da Aeronáutica, a qual reverberou midiaticamente, para comparação. Utilizamos a manchete publicada no site da Aeronáutica como uma amostra de controle, que será o ponto de partida para nossas comparações com os enunciados das outras mídias.

\section{Amostra de controle - manchete e primeiro parágrafo}

\section{Aeronáutica extrai com sucesso dados de gravador de voz do avião PR-SOM ${ }^{6}$}

O Centro de Investigação e Prevenção de Acidentes Aeronáuticos (Cenipa) divulgou nesta terçafeira (24/01) que conseguiu extrair com sucesso os dados do gravador de voz da cabine (CVR - cockpit voice recorder) do avião PR-SOM envolvido no acidente em Paraty (RJ), na última quintafeira (19/01). O chip de memória do gravador de voz da cabine do avião está sendo avaliado por uma equipe do laboratório de leitura e análise de dados de gravadores de voo (Labdata) do Cenipa. Em uma análise preliminar, os dados extraídos não apontam qualquer anormalidade nos sistemas da aeronave.

\section{Amostras de análise - manchete e primeiro parágrafo}

\section{Amostra A - Estadão.com}

\section{Áudios indicam desorientação de piloto do avião que caiu no mar e matou Teori ${ }^{7}$}

O Centro de Investigação e Prevenção de Acidentes Aeronáuticos (Cenipa) informou nesta terçafeira, 24, que análise preliminar dos áudios extraídos do gravador da cabine do avião que caiu no mar de Paraty (RJ), provocando a morte do ministro do Supremo Tribunal Federal Teori Zavascki e mais quatro pessoas, "não aponta qualquer anormalidade nos sistemas da aeronave". A gravação reforçou a hipótese de que houve desorientação espacial do piloto Osmar Rodrigues em razão do mau tempo na região.

\section{Amostra B - jornal Diario de Pernambuco}

\section{Áudios do avião revelam desorientação do piloto ${ }^{8}$}

Análise preliminar do áudio da cabine do avião que caiu e matou o ministro Teori Zavascki, do Supremo Tribunal Federal (STF), na semana passada, indica que houve uma desorientação espacial do piloto Osmar Rodrigues, segundo técnicos da Aeronáutica que investigam o caso. A conclusão final dependerá ainda de uma perícia técnica do avião, um King Air C90. A desorientação do piloto é, de acordo com a apuração conduzida pelo Centro de Investigação e Prevenção de Acidentes Aeronáuticos (Cenipa), a única hipótese em discussão para explicar a causa do acidente.

\subsection{As vozes}

Utilizamos a amostra de controle, que são as informações oficiais publicadas no site da FAB, para balizar as análises das amostras A e B. Ressaltamos que isso não significa aceitarmos o

\footnotetext{
${ }^{6}$ Disponível em http://zip.net/bhtC3J. Acesso em: 27.01.2017.

${ }^{7}$ Disponível em http://zip.net/bqtDT6. Acesso em: 27.01.2017.

${ }^{8}$ Disponível em http://zip.net/bctCXb. Acesso em: 27.01.2017.
} 
discurso da amostra de controle como verdadeiro. Suas impressões nos servirão para traçarmos um eixo de aproximação ou tentativa de ruptura pelos enunciados sob avaliação.

Primeiramente, tanto a amostra de controle como as duas outras se referem à extração do áudio do voo que caiu em Paraty. No entanto, a abordagem jornalística, nas amostras A e B, revelam vozes divergentes. Nas amostras A e B há um locutor L que, no caso, é o site do Estadão e o jornal Diario de Pernambuco. De ambos, enquanto meios de comunicação de massa, emergem os enunciados.

$\mathrm{Na}$ amostra A (Áudios indicam desorientação de piloto do avião que caiu no mar e matou Teori), fala um enunciador E1, que diz haver a possibilidade do piloto ter se desorientado durante o voo. Ao mesmo tempo, há um enunciador E2, mostrando justamente o contrário, que o piloto não se desorientou. Essa vOz refratária é percebida pela forma verbal no presente do indicativo "indicar". O verbo "indicar" auxilia na evocação dessa voz porque um de seus significados é "dar sugestão de" ${ }^{\prime}$.

A utilização desse verbo faz jus à natureza do assunto, que trata de uma investigação ainda no seu início e cheia de fatos que precisam ser provados. O verbo "indicar", assim como outros a exemplo do "evitar", "apontar", "sugerir", não encerram em si uma ação fechada. Deixam sempre abertas outras opções.

Essa característica enunciativa não é percebida na manchete da amostra $\mathrm{B}$ (Áudios do avião revelam desorientação do piloto). A utilização do verbo "revelar" mostra que se sobressai uma voz de um enunciador E1 conduzindo à interpretação de que o piloto se desorientou durante o voo. A forma verbal "revelar", também utilizada no presente do indicativo, tem como um dos sentidos tornar algo visível, perceptível ${ }^{10}$. A confrontação em relação a esse enunciado E1 é encontrada no texto que sequencia a manchete, o primeiro parágrafo da matéria, conforme é exposto já no primeiro período do primeiro parágrafo:

"Análise preliminar do ándio da cabine do avião que caiu e matou o ministro Teori Zavascki, do Supremo Tribunal Federal (STF), na semana passada, indica que houve uma desorientação espacial do piloto Osmar Rodrigues, segundo técnicos da Aeronáutica que investigam o caso."

No trecho acima, verificamos a atuação de um enunciador E2 que se contrapõe ao que foi dito por E1 no título principal. No período, utiliza-se o verbo "indicar", que não encerra uma ação, e um termo lexical que também possui características não conclusivas: "preliminar". Esse termo, inclusive, está presente na amostra de controle e desse se valeram os dois meios midiáticos para desenvolver a construção do conteúdo em formato noticioso.

No entanto, observamos que os enunciadores de ambas as amostras que defendem ter havido uma desorientação do piloto durante o voo refletem uma voz do enunciador da amostra de controle, que chamaremos Ec, que diz haver essa possibilidade, embora de forma subentendida. Encontramos essa interpretação ao analisar o seguinte período: "Em uma análise preliminar, os dados extraídos não apontam qualquer anormalidade nos sistemas da aeronave".

Raciocinando à luz de Ducrot (1997), podemos afirmar que, no excerto acima, há uma voz que indica não ter havido problemas no voo, que seria o Ec1 da amostra de controle. Mas, ao mesmo tempo, há outra voz, que chamaremos Ec2, afirmando que, se não houve anormalidade durante o voo, então, houve com o piloto. Foi a essa voz, subliminar, que recorreram os locutores - meios de comunicação - ao construírem seus enunciados.

\subsection{A ideologia e o discurso}

\footnotetext{
${ }^{9}$ Fonte: Houaiss.

${ }^{10}$ Idem.
} 
Dissemos que o alocutário, elemento da teoria polifônica de Ducrot (1997), é, ao mesmo tempo, para o qual são direcionados os discursos e também quem fala nesses discursos. Apontando essa reflexão para as amostras, identificamos o alocutário A como a audiência, o destinatário desses enunciados, que está dividido em dois grandes grupos: os que acreditam ter sido apenas um acidente e os que desconfiam que possa ter havido atentado.

Observamos isso ao identificar o ciclo ideológico que o léxico utilizado obedece. $\mathrm{Na}$ amostra A (Áudios indicam desorientação de piloto do avião que cain no mar e matou Teori), temos um alocutário A1 próximo da ideia de que foi acidente. Esse alocutário comunga com o que enuncia o enunciador E1. Já o enunciado E2, como analisamos no item anterior, mostra que o piloto pode não ter se desorientado. Essa voz se junta à do alocutário A2, que também pensa da mesma. Dessa forma, construindo dualmente o discurso de que houve ou não desorientação do piloto, a mídia consegue conversar com a sua audiência, que é híbrida, possui opiniões divergentes na sua essência.

Esse raciocínio também inclui um alocutário que chamaremos A3, que dialoga com o enunciador E3, cuja posição é justamente a dúvida, não ter uma opinião formada. Esses elementos estão naturalmente impressos aos enunciados, que ora tendem para um lado, ora para outro. Essa relação é aparentemente quebrada na amostra B (Áudios do avião revelam desorientação do piloto), que assume uma posição no enunciado principal de que o piloto se desorientou, mas é confrontada pelo enunciador $\mathrm{E} 2$, que atua no texto e diz justamente o contrário.

A partir desse raciocínio, refletimos que o léxico utilizado obedece a um ciclo ideológico de significações dúbias, que ora convergem, ora divergem entre si. Os verbos "indicar" e "revelar" são utilizados no centro de uma cadeia de significação constituída de referências heterogêneas. Percebemos a dualidade certeza/dúvida durante nessas formas verbais, assim como em outros termos lexicais que são utilizados para alimentá-la: "análise preliminar", "não aponta qualquer anormalidade".

O interessante é que todos esses enunciadores que apontamos neste estudo emanam de um só enunciador principal presente no discurso indireto: os técnicos da Aeronáutica. A partir do que eles disseram, a mídia constrói interpretações utilizando-se de um discurso heterogêneo, para dialogar com a sua audiência, igualmente híbrida.

Esse discurso midiático, de estabelecer oposição e confrontação de ideias, apoia-se em uma formação discursiva que reside no discurso técnico-científico, que se utiliza da dúvida e da comprovação para produzir suas evidências. E esse discurso atravessa o campo discursivo midiático que, além de fazer o acontecimento ser interessante sob o ponto de vista jornalístico, também precisa ancorar sua credibilidade nos pilares da ciência.

\section{CONSIDERAÇÕES FINAIS}

Os enunciados midiáticos possuem uma função jornalística de informar, de chamar a atenção da audiência para assuntos considerados importantes, ou seja, que atendam às expectativas dos valores-notícia. Essa audiência com a qual os veículos midiáticos dialogam é heterogênea, proveniente de camadas sociais diversificadas e, por sua vez, inserida em contextos diferenciados.

O universo híbrido com o qual dialogam os enunciados do noticiário os torna também híbridos. Assumimos a ideia de que não poderia ser diferente, já que o objetivo maior de um jornal, de um site de notícias ou de uma TV, por exemplo, é a conquista da audiência. Com base nessa relação, pudemos verificar e analisar a presença da polifonia nesses enunciados jornalísticos, cuja utilização está fortemente voltada para a adesão do alocutário. Um enunciado com várias vozes comunica-se com vários segmentos. Os títulos e as matérias jornalísticas, seguindo essa ótica, são enunciados heterogêneos, porque dialogam com universos também heterogêneos. 
Verificamos que essa polifonia no material jornalístico é essencialmente marcada pela oposição, pela presença de vozes opostas, que dialogam com contextos sócio-históricos diferentes. Os conteúdos noticiosos trazem em si cargas ideológicas produzidas a partir de contextos históricos diversos, tanto atuais, quanto históricos.

Por tudo o que foi analisado, reafirmamos que a característica polifônica resulta do contato do meio de comunicação com um universo sócio-histórico diversificado, que reúne segmentos sociais heterogêneos. E o próprio meio midiático também integra esse universo e reproduz dele ideologias, discursos naturalizados e toda uma gama de ideias e pensamentos produzidos através de filtros ideológicos, sociais e históricos.

\section{REFERÊNCIAS BIBLIOGRÁFICAS}

BAKHTIN, Mikhail. Marxismo e Filosofia da Linguagem. 13 ed. São Paulo: Hucitec, 2009.

Os gêneros do discurso. In: . Estética da criação verbal. 5 ed. São Paulo: Martins Fontes, 2010a. p. 261-306.

Problemas da poética de Dostoiévski. 5 ed. Rio de Janeiro: Forense Universitária, 2010b.

BARROS, Maria. (RE) Descobrindo o discurso polifônico em textos de alunos universitários: a busca da subjetividade e da alteridade. 2007. 226 p. Tese (Doutorado em Letras) - Instituto de Letras, Universidade Federal da Bahia, Bahia.

DUCROT, Oswald. O dizer e o dito. Ed. (n/d). Campinas: PONTES, 1987.

KOCH, Ingedore. A inter-ação pela linguagem. 10 ed. São Paulo: Contexto, 2007.

MAINGUENAU, Dominique. A propósito do Ethos. In: MOTTA, Ana R.; SALGADO, Luciana (orgs.). Ethos discursivo. Contexto, 2008, capítulo 1, p. 11-29.

Análise de textos de comunicação. 2. ed. São Paulo: Cortez, 2002. p. 19-56.

ORLANDI, Eni. Análise de Discurso: princípios e procedimentos. 8 ed. Campinas: Pontes, 2009.

TRAQUINA, Nelson. Teorias do Jornalismo: a tribo jornalística - uma comunidade interpretativa transnacional - vol. II. Florianópolis: Insular, 2. ed., 2008.

Recebido em 24/05/2017

Aceito em 01/06/2017

Publicado em 05/06/2017 